\title{
Dinâmica de Populações e Fitossociologia de Plantas daninhas no Cultivo do Feijão-Caupi e Mandioca no Sistema Corte e QueIMa com o Uso de ARAdo ${ }^{1}$
}

\author{
Phytosociology of Weeds in Cowpea and Cassava Crops under the Slash-and-Burn with Plow
}

\author{
MARQUES, L.J.P. ${ }^{2}$, SILVA, M.R.M. ${ }^{3}$, LOPES, G.S. ${ }^{4}$, CORREA, M.J.P. ${ }^{5}$, ARAUJO, M.S. ${ }^{6}$, \\ COSTA, E.A. ${ }^{7}$ e MUNIZ, F.H. ${ }^{8}$
}

\begin{abstract}
RESUMO - Este estudo investigou a composição florística das plantas daninhas em área queimada durante três anos agrícolas. A pesquisa foi conduzida no município de Zé Doca, Maranhão. O preparo da área no primeiro ano agrícola (2006/2007) foi realizado com corte e queima da vegetação para o cultivo de milho seguido do feijão-caupi. No segundo e no terceiro ano agrícola, o preparo da área consistiu de aração para o cultivo do milho seguido de mandioca (2007/2008) e depois para o feijão-caupi em sucessão à cultura de mandioca (2008/2009). A coleta das plantas daninhas ocorreu nas culturas de feijão-caupi e mandioca aos 30 e 60 dias após a semeadura (DAS), no primeiro e no segundo ano agrícola, respectivamente, e no feijão-caupi aos 30 DAS do terceiro ano agrícola, com retângulo $(0,5 \times 0,3 \mathrm{~m})$ lançado 10 vezes ao acaso na área cultivada. A cada lançamento, as plantas daninhas foram colhidas, para contagem, identificação, secagem e, assim, obter os indices fitossociológicos. O fogo reduziu a diversidade e o número das plantas daninhas. As espécies com maior valor de IVI foram Imperata brasiliensis, Sida glomerata e Corchorus argutus, após o fogo na cultura do feijãocaupi; e Juncus sp., Spermacoce verticillata, Aeschynomene americana e Cyperus sp., após preparo da área com aração nas culturas de mandioca e feijão-caupi. As plantas de capoeira ocorreram depois da queima, porém sua importância foi reduzida com o passar do tempo.
\end{abstract}

Palavras-chave: Vigna unguiculata, Manihot sp., sistema itinerante, aração, comunidade infestante.

\begin{abstract}
This study investigated the floristic composition of weeds in a burnt area in Zé Doca, Maranhão, during three agricultural years. The preparation of the area at the first crop year (2006/ 2007) was by slash-and-burn for maize cultivation, followed by cowpea. In the second and third crop years, the preparation of the area consisted of plowing for maize cultivation, followed by cassava (2007/2008) and later, by cowpea in rotation with cassava (2008/2009). Weed collection in the cowpea and cassava crops was carried out 30 and 60 days after sowing (DAS) during the first and second agricultural year, respectively, and cowpea crop at 30 DAS in the third crop year with a rectangle $(0.5 \times 0.3 \mathrm{~m})$ randomly placed in the area. Every launch was conducted to evaluate the aerial parts of the weeds harvested for counting, identification and drying to obtain the phytosociological indices. The slash-and-burn practice reduces the variety and number of weeds. Species with the highest IVI were Imperata brasiliensis, Sida glomerata and Corchorus argutus after slash-and-burn in the cowpea culture; and Juncus sp., Spermacoce verticillata, Aeschynomene americana and Cyperus sp. after plowing in the cassava and cowpea cultures. Secondary vegetation plants occurred after burn, but were reduced over time.
\end{abstract}

Keywords: Vigna unguiculata, Manihot sp., slash-and-burn, plowing, weed community.

1 Recebido para publicação em 30.11.2010 e aprovado em 27.5.2011.

2 Engo-Agro-., Mestre em Agroecologia, Universidade Estadual do Maranhão - UEMA, Campus Universitário Paulo VI, s/n. Tirirical, 65055-970 São Luís-MA, <luiz1000x@yahoo.com.br>; ${ }^{3}$ Prof ${ }^{\mathfrak{a}}$ Adjunta, Dr ${ }^{\mathrm{a}}$, Dep. de Fitotecnia e Fitossanidade, UEMA, <rmalheir@yahoo.com.br>; ${ }^{4}$ Eng - -Agr $\underline{a}$, Doutoranda em Agronomia, Produção Vegetal, UNESP, Jaboticabal, $<$ gslopes11@yahoo.com.br>; ${ }^{5}$ Prof ${ }^{\mathrm{a}}$. Adjunta, Dr ${ }^{\mathrm{a}}$, Dep. de Química e Biologia, UEMA, <mjcorreazea@hotmail.com>; ${ }^{6}$ Eng - -Agr ${ }^{\mathrm{a}}$., UEMA, <mgrth_22@hotmail.com>; ${ }^{7}$ Graduanda do Curso de Agronomia, UEMA, <elizacosta17@yahoo.com.br>; ${ }^{8}$ Prof ${ }^{\mathrm{a}}$ Adjunta, Drª , Dep. de Química e Biologia, UEMA, <fhmuniz@yahoo.com>.

Planta Daninha, Viçosa-MG, v. 29, p. 981-989, 2011. Número Especial 


\section{INTRODUÇÃO}

Para a agricultura familiar da região Nordeste, os cultivos de feijão-caupi e mandioca são considerados relevantes na dieta alimentar. O feijão-caupi é alternativa de renda e alimento para a população de baixa renda dessa região (Oliveira et al., 2003), enquanto a cultura de mandioca (Manihot sp.) é usada na produção de farinha. Para essas duas culturas, a redução da produtividade é atribuída, entre outros fatores, à competição com as plantas daninhas (Johanns \& Contiero, 2006; Freitas et al., 2009).

Geralmente, na Amazônia, o cultivo de feijão-caupi e de mandioca é realizado no sistema de corte e queima ou sistema itinerante, que se baseia no corte raso da vegetação secundária (capoeira), seguido por queima e cultivo de culturas anuais por dois ou três anos e posterior abandono da área para o pousio. Nesse sistema, a biomassa do extrato herbáceo é favorecida pela redução do pousio (Roder et al., 1997).

Para inferir o impacto dos sistemas de manejo e das práticas agrícolas sobre a dinâmica de crescimento e ocupação de comunidades infestantes em agroecossistemas, é importante a aplicação de índices fitossociológicos. Esses indices permitem o conhecimento das plantas daninhas mais importantes dentro da comunidade infestante, para as quais se devem determinar alternativas de manejo ou mesmo mudanças no sistema, a fim de viabilizar o seu controle. Segundo Pitelli (2000), os indices fitossociológicos são determinados pela densidade relativa, que reflete a participação numérica de indivíduos de uma determinada espécie na comunidade; pela frequência relativa, que se refere à porcentagem que representa a frequência de uma população em relação à soma das frequências das espécies que constituem a comunidade; pela dominância relativa, que representa o ganho de biomassa de uma espécie na comunidade; e pela importância relativa, que é uma avaliação ponderada desses índices e indica as espécies mais importantes em termos de infestação das culturas.

No Estado do Maranhão, estudos fitossociológicos foram realizados por Marques et al. (2010) em área manejada com capoeira triturada. Araujo et al. (2007) identificaram e avaliaram a agressividade potencial das plantas daninhas em agroecossistema ecológico. Assim, este trabalho teve por objetivo avaliar a composição florística e fitossociológica das plantas daninhas no sistema de corte e queima no município de Zé Doca-MA, durante três anos de cultivos agrícolas, nas culturas de feijão e mandioca.

\section{MATERIAL E MÉTODOS}

A pesquisa foi conduzida no assentamento PA Belém, do município de Zé Doca-MA ( $3^{\circ} 14^{\prime}$ $35^{\prime \prime}$ de latitude sul e $45^{\circ} 49^{\prime} 26^{\prime \prime}$ de longitude oeste), nos anos agrícolas de 2006/2007, 2007/ 2008 e 2008/2009. O clima da região, segundo a classificação de Thorntwaite, é do tipo B2rA'a', clima úmido do tipo B2, com pequena ou nenhuma deficiência de água, megatérmico com precipitações em torno de 1.600 a $2.000 \mathrm{~mm}$ anuais, com predominância dos totais pluviométricos nos meses de fevereiro e março. Os tipos de solo predominantes na região são Plintossolo e Argissolo Vermelho-Amarelo (GEPLAN, 2002).

No primeiro ano agrícola (2006/2007), a área foi preparada com corte e queima da vegetação secundária para o plantio de milho-catingueiro seguido de feijão-caupi BRS Guariba. No segundo ano (2007/2008), o preparo da área foi realizado com aração, para o cultivo do milho-catingueiro seguido de mandioca; e no terceiro ano agrícola (2008/2009) foi realizada a colheita da mandioca em maio, seguida do preparo da área com arado e semeadura do mesmo cultivar de feijão-caupi. A semeadura das culturas foi realizada, manualmente, em covas sem espaçamento definido e sem adubação, numa área de $800 \mathrm{~m}^{2}$. O manejo das plantas daninhas foi por meio de capina manual, no primeiro e segundo anos agrícolas após as avaliações das plantas daninhas.

A coleta das plantas daninhas ocorreu aos 30 e 60 dias após a semeadura (DAS), nos anos agrícolas de 2006/2007 e 2007/2008. No terceiro ano (2008/2009), a avaliação ocorreu apenas aos 30 DAS. Na amostragem das plantas daninhas foi utilizado um amostrador de área de $0,15 \mathrm{~m}^{2}$, lançado ao acaso por 10 vezes. A cada lançamento, as partes aéreas das plantas daninhas colhidas foram avaliadas por 
meio de identificação, contagem e obtenção de massa seca. As identificações das plantas daninhas foram realizadas por meio do exame de material, consulta à literatura e envio de exsicatas ao laboratório de botânica - herbário da Embrapa Amazônia Oriental, em Belém/ Pará. O peso da matéria seca foi obtido após manutenção em estufa com ventilação forçada de ar a $70{ }^{\circ} \mathrm{C}$, até atingir peso constante. Esses dados foram usados para determinação dos parâmetros fitossociológicos: densidade relativa (De.R), calculada pela fórmula proposta por Curtis \& Mc Intosh (1950), frequência absoluta (Fr.) e relativa (Fr.R), dominância relativa (Do.R) e índice de valor de importância (IVI), que foram calculados por fórmulas propostas por Mueller-Dombois \& Ellemberg (1974).

$\mathrm{O}$ indice de similaridade da composição florística foi determinado entre as avaliações (30 e 60 DAS) e entre anos agrícolas (2006/ 2007, 2007/2008 e 2008/2009). Utilizou-se o indice de Jaccard e a construção de dendrograma baseado no método da média do grupo (UPGMA), em que o agrupamento foi a partir da média aritmética dos seus elementos. Na análise de classificação foram utilizados os programas Matriz, Coef e Cluster, do programa FITOPAC (Shepherd, 1994). Também foi calculado o indice de diversidade de Shannon-Weaver ( $\left.\mathrm{H}^{\prime}\right)$ citado por Magurran (1988) para cada avaliação nos anos agrícolas trabalhados:

$$
H^{\prime}=-\sum_{i=1}^{S} p_{i} \ln p_{i}
$$

em que $l n$ é o logaritmo neperiano; $p i=n i / N$; ni é o número de indivíduos amostrados da espécie $i$; e $N$ é o número total de indivíduos amostrados.

\section{RESULTADOS E DISCUSSÃO}

No primeiro ano agrícola (2006/2007), após o corte e queima, foram coletados na cultura do feijão-caupi 139 indivíduos, assim distribuídos: $28,78 \%$ na classe monocotiledônea e $71,22 \%$ na classe dicotiledônea. Entre as 11 famílias identificadas, Malvaceae apresentou o maior número de espécies (Tabela 1). No segundo ano agrícola (2007/2008), na cultura da mandioca, foram coletados 661 indivíduos, sendo 40,4\% pertencentes à classe monocotiledônea e 59,6\% à classe dicotiledônea. Foram identificadas 13 famílias, das quais se destacaram, em riqueza de espécies, Cyperaceae, Malvaceae e Rubiaceae. No terceiro ano agrícola (2008/2009), em que a área foi preparada com arado e cultivada com feijão-caupi, foram obtidos 593 indivíduos, sendo $98,98 \%$ na classe monocotiledônea e $1,2 \%$ na classe dicotiledônea. Entre os indivíduos obtidos, somente três famílias botânicas foram identificadas, e a mais importante foi Cyperaceae. Verificou-se que, no primeiro ano agrícola, o número de indivíduos coletados foi bem menor comparado aos dois últimos anos; isso decorre do preparo do solo com o uso do fogo, que é eficiente em eliminar as sementes das espécies mais sensíveis. Segundo Leal et al. (2006), a queima altera a seleção das espécies pioneiras, reduzindo a taxa de germinação e o banco de sementes, comparada com os estoques antes da queima. Também se observa que nos três anos agrícolas houve mudança na dominância das classes e das famílias, em razão do preparo do solo, que atuou na dinâmica das espécies no sistema de produção agrícola.

$\mathrm{Na}$ avaliação do índice de diversidade de Shannon nos três anos agrícolas, foram observadas variações conforme a prática de manejo. No primeiro ano, foi constatado que a queima seguida do cultivo de feijão-caupi reduziu a diversidade das plantas daninhas aos 30 DAS $\left(H^{\prime}=1,59\right)$, porém houve ligeiro aumento aos 60 DAS $(2,2)$ (Tabela 2). Após a queima, a redução do índice de Shannon também foi observada nos trabalhos de Leal et al. (2006), que encontraram valores de diversidade de 1,29 no Estado do Pará, e de Ikeda et al. (2008), que observaram valores de 1,27 em trabalhos de banco de semente em área de cerrado queimado. Ainda segundo Leal et al. (2006), a média do número de espécies antes da queima foi de 20,7 e, depois da queima, de 5,7. No segundo ano agrícola, o preparo da área com arado e cultivo de mandioca aumentou a diversidade aos 30 DAS $\left(\mathrm{H}^{\prime}=2,1\right)$ e reduziu aos 60 DAS $\left(H^{\prime}=1,87\right)$. O aumento da diversidade aos 30 DAS no segundo ano ocorreu provavelmente devido ao preparo do solo com uso do arado, em que o revolvimento do solo espalhou sementes e outros propágulos presentes nas camadas mais profundas, trazendo-os para a camada mais superficial, aumentando assim 
o número de espécies presentes na área na fase inicial de desenvolvimento da cultura A redução aos 60 DAS pode ser consequência da competição interespecífica das plantas daninhas, em que espécies mais competitivas tendem a predominar na área. No terceiro ano agrícola, em área preparada com arado seguido do cultivo de feijão-caupi, ocorreu simplificação de espécies com índice de diversidade baixo aos 30 DAS $\left(H^{\prime}=0,87\right)$. Essa redução da diversidade é explicada pela grande infestação de Cyperaceae, que pode ter sido estimulada pelas práticas de manejo com arado, além das fortes chuvas observadas nesse período.

Tabela 1 - Principais plantas daninhas identificadas nos anos agrícolas de 2006/2007 (com área preparada com o corte e queima e cultivada com feijão-caupi) e 2007/2008 e 2008/2009 (com preparo da área com arado cultivada com mandioca e feijão-caupi, respectivamente) no município de Zé Doca-MA

\begin{tabular}{|c|c|c|c|c|}
\hline \multirow{2}{*}{ Família } & \multirow{2}{*}{ Nome científico } & \multicolumn{3}{|c|}{ Ano agrícola } \\
\hline & & $2006 / 2007$ & $2007 / 2008$ & $2008 / 2009$ \\
\hline \multirow{3}{*}{ Asteraceae } & Bidens pilosa $\mathrm{L}$. & $\mathrm{X}$ & & \\
\hline & Elephantopus mollis Kunth. & $\mathrm{X}$ & & \\
\hline & Emilia coccinea $($ Sims) G. Don & & $\mathrm{X}$ & \\
\hline Commelinaceae & Murdania nudiflora (L.) Brenan & & & $\mathrm{X}$ \\
\hline \multirow{8}{*}{ Cyperaceae } & Cyperus compressus L. & & $\mathrm{X}$ & $\mathrm{X}$ \\
\hline & Cyperus diffusus Vahl. & & $\mathrm{X}$ & \\
\hline & Cyperus flavus J. Presl \& C. Presl & & $\mathrm{X}$ & $\mathrm{X}$ \\
\hline & Cyperus iria $\mathrm{L}$. & & & $\mathrm{X}$ \\
\hline & Cyperus luzulae (L.) Retz. & & & $\mathrm{X}$ \\
\hline & Cyperus surinamensis Rottb. & & $\mathrm{X}$ & \\
\hline & Cyperus spp. & $\mathrm{X}$ & & $\mathrm{X}$ \\
\hline & Rhynchospora nervosa (Vahl) Boeck. & & $\mathrm{X}$ & \\
\hline Fabacea-Caesalpinoideae & Senna obtusifolia (L.) H. S. Irwin \& Barneby & $\mathrm{X}$ & & \\
\hline \multirow{2}{*}{ Fabacea-Faboidea } & Aeschynomene americana $\mathrm{L}$. & $\mathrm{X}$ & $\mathrm{X}$ & \\
\hline & Calopogonium muconoides Deves & $\mathrm{X}$ & $\mathrm{X}$ & \\
\hline Juncaceae & Juncus sp. & & $\mathrm{X}$ & \\
\hline \multirow{2}{*}{ Lamiaceae } & Hyptis suaveolens (L.) Poit. & & $\mathrm{X}$ & \\
\hline & Marsypianthes chamaedrys (Vahl) Kuntze & $\mathrm{X}$ & & \\
\hline \multirow{4}{*}{ Malvaceae } & Pavonia cancellata (L.) Cav. & $\mathrm{X}$ & $\mathrm{X}$ & $\mathrm{X}$ \\
\hline & Sida decumbens A. St.-Hil. \& Naudin & $\mathrm{X}$ & $\mathrm{X}$ & $\mathrm{X}$ \\
\hline & Sida glomerata Cav. & $\mathrm{X}$ & $\mathrm{X}$ & \\
\hline & Corchorus argutus Kurth & $\mathrm{X}$ & $\mathrm{X}$ & \\
\hline Melastomataceae & Pterolepis trichotoma (Rottb.) Cogn. & & $\mathrm{X}$ & \\
\hline Onagraceae & Ludwigia hyssopifolia (G. Don) Exell & $\mathrm{X}$ & $\mathrm{X}$ & \\
\hline Phyllanthaceae & Phyllanthus niruri L. & & $\mathrm{X}$ & \\
\hline \multirow{2}{*}{ Plantaginaceae } & Lindernia crustaceae (L.) I. V. Müell & & $\mathrm{X}$ & \\
\hline & Scoparia dulcis L. & & $\mathrm{X}$ & \\
\hline \multirow{3}{*}{ Poaceae } & Axonopus compressus (Sw) P. Beauv. & & $\mathrm{X}$ & \\
\hline & Imperata brasiliensis Trin. & $\mathrm{X}$ & & \\
\hline & Panicum laxum Sw. & & $\mathrm{X}$ & \\
\hline \multirow{2}{*}{ Rubiaceae } & Spermacoce latifolia Aubl. & $\mathrm{X}$ & $\mathrm{X}$ & \\
\hline & Spermacoce verticillata $\mathrm{L}$. & & $\mathrm{X}$ & \\
\hline Schizaeaceae & Lygodium venustum $\mathrm{Sw}$. & $\mathrm{X}$ & & \\
\hline Turneraceae & Turnera ulmifolia $\mathrm{L}$. & $\mathrm{X}$ & $\mathrm{X}$ & \\
\hline
\end{tabular}


Tabela 2 - Índice de diversidade (H') entre os anos agrícolas 2006/2007 (cultivo de feijão-caupi em área preparada com o corte e queima da vegetação), 2006/2007 e 2007/2008 (cultivo de mandioca e feijão-caupi, respectivamente, com preparo da área com arado), aos 30 e 60 DAS

\begin{tabular}{|l|c|c|}
\hline \multirow{2}{*}{ Ano agrícola/cultivo } & \multicolumn{2}{|c|}{ Avaliação } \\
\cline { 2 - 3 } & 30 DAS & 60 DAS \\
\hline $2006 / 2007$ - Feijão-caupi & 1,59 & 2,20 \\
\hline $2007 / 2008$ - Mandioca & 2,10 & 1,87 \\
\hline $2008 / 2009$ - Feijão-caupi & 0,87 & ---- \\
\hline
\end{tabular}

I. brasiliensis foi a espécie de maior IVI $(87,37 \%)$ após o corte e queima aos 30 DAS do cultivo do feijão-caupi (2006/2007). O alto valor de IVI dessa espécie se deve à De.R $(41,67 \%)$, que foi a maior no primeiro ano agrícola e representa o dobro dos valores de Fr.R e Do.R (Tabela 3). O capim-furão (I. brasiliensis) é uma planta invasora perene que ocorre com frequência em pastagens degradadas e áreas cultivadas. Em casos de infestação mais intensa das pastagens, a disponibilidade de forragem é reduzida para niveis que comprometem a produção animal (Carvalho et al., 2000). O capim-furão não foi registrado nos anos agrícolas posteriores (2007/2008 e 2008/2009). Rodrigues et al. (2007), avaliando a composição florística de áreas trituradas após quatro anos de cultivos anuais, constataram baixos valores de densidade relativa $(8,5)$ de I. brasiliensis. A reduzida densidade ou mesmo ausência desta espécie em cultivos anuais pode estar relacionada com a adaptabilidade a cultivos perenes, como as pastagens que sofrem interferência de pastejo e fogo, diferentemente de cultivos anuais com práticas de manejo mais intensas e diferenciadas, como aração e capinas, além da rotação de cultura. Segundo Meira Neto (2005), as espécies Baccharis trimera, Blechnum serrulatum, I. brasiliensis e Pteridium aquilinum, quando ocorrem associadas no estrato subarbustivo-arbustivo, são indicadoras dos impactos de passagem de fogo e pastejo bovino; isso porque o fogo selecionaria as espécies resistentes a ele, as hemicriptófitas, e o pastejo, as espécies tóxicas e impalatáveis, dando origem à associação de espécies hemicriptófitas, não palatáveis e/ou tóxicas.

As espécies da família Malvaceae (S. glomerata, S. decumbens, C. argutus e $P$. cancellata) também foram importantes após o fogo tanto aos 30 como aos 60 DAS. No entanto, houve decréscimo nos valores de IVI dessas espécies nos anos subsequentes (Tabelas 3 e 4). A redução do IVI das espécies dessa família a partir do segundo ano agrícola mostra que as práticas de manejo aração e rotação de cultura interferem no desenvolvimento dessas espécies.

S. glomerata foi uma espécie importante na cultura do feijão-caupi no primeiro ano agrícola em razão dos altos valores de IVI aos 30 DAS, com destaque para De.R e Fr.R, e aos 60 DAS, para a De.R e Do.R. Espécies do gênero Sida sp. (Sida glaziovii) também foram observadas por Freitas et al. (2009), avaliando os periodos de interferência na cultura do feijão-caupi, com altos valores de densidade. No Maranhão, Araujo et al. (2007), trabalhando com diferentes adubos verdes para a supressão de plantas daninhas, constataram que Sida sp. foi a terceira planta de maior ocorrência, e

Tabela 3 - Densidade relativa (De.R), frequência relativa (Fr.R), dominância relativa (Do.R) e índice de valor de importância (IVI) das principais plantas daninhas na cultura do feijão-caupi em área manejada com corte e queima, em Zé Doca-MA, aos 30 e 60 DAS, no ano agrícola 2006/2007

\begin{tabular}{|c|c|c|c|c|c|c|c|c|c|}
\hline \multicolumn{10}{|c|}{$2006 / 2007$} \\
\hline \multirow{2}{*}{ Espécie } & \multicolumn{4}{|c|}{$30 \mathrm{DAS}$} & \multirow{2}{*}{ Espécie } & \multicolumn{4}{|c|}{$60 \mathrm{DAS}$} \\
\hline & De.R & Fr.R & Do.R & IVI & & De.R & Fr.R & Do.R & IVI \\
\hline Imperata brasiliensis & 41,67 & 21,05 & 24,65 & 87,37 & Sida glomerata & 26,61 & 13,51 & 26,69 & 66,71 \\
\hline Sida glomerata & 30,00 & 26,32 & 19,50 & 75,81 & Corchorus argutus & 19,28 & 13,51 & 11,17 & 43,96 \\
\hline Sida decumbens & 6,67 & 10,53 & 19,41 & 36,60 & Pavonia cancellata & 7,23 & 8,11 & 18,82 & 34,16 \\
\hline Corchorus argutus & 10,00 & 10,53 & 5,62 & 26,15 & Cyperus spp. & 15,66 & 10,81 & 1,50 & 27,97 \\
\hline Spermacoce latifolia & 1,67 & 5,26 & 9,56 & 16,49 & Calopogonium muconoides & 4,82 & 10,81 & 9,97 & 25,6 \\
\hline Bidens pilosa & 1,67 & 5,26 & 7,62 & 14,55 & Sena obtusifolia & 3,61 & 8,11 & 4,45 & 16,18 \\
\hline Pavonia cancellata & 1,67 & 5,26 & 4,18 & 11,11 & Lygodium venustum & 2,41 & 5,41 & 6,68 & 14,50 \\
\hline
\end{tabular}


Tabela 4 - Densidade relativa (De.R), frequência relativa (Fr.R), dominância relativa (Do.R) e índice de valor de importância (IVI) das principais plantas daninhas na cultura de mandioca (2007/2008) e feijão-caupi (2008/2009) em área preparada com arado, em Zé Doca-MA, aos 30 e 60 DAS

\begin{tabular}{|c|c|c|c|c|c|c|c|c|c|c|c|c|c|c|}
\hline \multicolumn{10}{|c|}{$2007 / 2008$} & \multicolumn{5}{|c|}{$2008 / 2009$} \\
\hline \multirow{2}{*}{ Espécie } & \multicolumn{4}{|c|}{$30 \mathrm{DAS}$} & \multirow{2}{*}{ Espécie } & \multicolumn{4}{|c|}{ 60DAS } & \multirow{2}{*}{ Espécie } & \multicolumn{4}{|c|}{30 DAS } \\
\hline & De.R & Fr.R & Do.R & IVI & & De.R & Fr.R & Do.R & IVI & & De.R & Fr.R & Do.R & IVI \\
\hline Juncus sp. & 48,74 & 4,55 & 10,16 & 63,44 & $\begin{array}{l}\text { Spermacoce } \\
\text { verticillata }\end{array}$ & 4,28 & 18,52 & 45,98 & 68,77 & Cyperus spp. & 71,7 & 42,1 & 61,4 & 175,2 \\
\hline $\begin{array}{l}\text { Aeschynomene } \\
\text { americana }\end{array}$ & 1,05 & 3,03 & 30,28 & 34,36 & Juncus sp. & 28,88 & 11,11 & 2,47 & 42,46 & Cyperus iria & 20,3 & 21,1 & 32,2 & 73,5 \\
\hline Cyperus diffusus & 10,92 & 12,12 & 5,42 & 28,47 & diffusus & 14,97 & 14,81 & 3,07 & 32,86 & Cyperus flavus & 3,9 & 10,5 & 3,1 & 17,5 \\
\hline Sida glomerata & 3,99 & 6,06 & 12,35 & 22,41 & Cyperus flavus & 22,99 & 3,70 & 2,92 & 29,62 & $\begin{array}{l}\text { Cyperus } \\
\text { compressus }\end{array}$ & 2,51 & 5,26 & 1,67 & 9,44 \\
\hline $\begin{array}{l}\text { Corchorus } \\
\text { argutus }\end{array}$ & 2,73 & 9,09 & 10,43 & 22,25 & \begin{tabular}{|l} 
Spermacoce \\
latifolia
\end{tabular} & 3,21 & 11,11 & 14,02 & 28,34 & $\begin{array}{l}\text { Pavonia } \\
\text { cancellata }\end{array}$ & 0,34 & 5,26 & 1,67 & 6,65 \\
\hline $\begin{array}{l}\text { Spermacoce } \\
\text { latifolia }\end{array}$ & 1,05 & 4,55 & 7,46 & 13,06 & $\begin{array}{l}\text { Ludwigia } \\
\text { hyssopifolia }\end{array}$ & 2,14 & 11,11 & 8,18 & 21,43 & $\begin{array}{l}\text { Murdania } \\
\text { nudiflora }\end{array}$ & 0,5 & 5,26 & 0,21 & 5,98 \\
\hline $\begin{array}{l}\text { Rhynchospora } \\
\text { nervosa }\end{array}$ & 5,67 & 4,55 & 2,32 & 12,54 & Sida decumbens & 1,07 & 3,70 & 9,10 & 13,87 & $\begin{array}{l}\text { Sida } \\
\text { decumbens }\end{array}$ & 0,17 & 5,26 & 0,19 & 5,62 \\
\hline $\begin{array}{l}\text { Spermacoce } \\
\text { verticillata }\end{array}$ & 2,10 & 6,06 & 3,56 & 11,72 & $\begin{array}{l}\text { Aeschynomene } \\
\text { americana }\end{array}$ & 0,53 & 3,70 & 7,57 & 11,81 & & & & & \\
\hline
\end{tabular}

Sida glaziovii, a quarta com maior frequência. As condições de crescimento do gênero Sida spp. estão associadas a ambientes degradados (Galindo et al., 2008), como aqueles manejados com o fogo, que provoca perdas de nutrientes, exposição do solo às intempéries climáticas, lixiviação e compactação do solo.

As plantas daninhas Juncus sp., A. americana e $S$. verticillata foram as espécies que apresentaram maior IVI aos 30 e 60 DAS do cultivo da mandioca no segundo ano agrícola (2007/2008), com preparo da área com arado (Tabela 4). Juncus sp. foi a espécie de maior IVI aos 30 DAS e segundo maior IVI aos 60 DAS do ano agrícola 2007/2008, na cultura da mandioca, enquanto $A$. americana foi a espécie com o segundo maior IVI aos 30 DAS desse período. Juncus sp. apresentou a maior De.R, e A. americana, a maior Do. $\mathrm{R}$, porém as duas espécies apresentaram baixa Fr.R, o que favorece um controle mais localizado.

S. verticillata e S. latifolia pertencem à família Rubiaceae e também foram importantes no segundo ano agrícola $(2007 / 2008)$, com a primeira apresentando o maior IVI. Aos 30 e 60 DAS, essas espécies apresentaram destaque para a Fr.R e Do.R. Ikeda et al. (2008), na área de cerrado queimada, constataram que a família Rubiaceae foi a mais importante - representada pelas espécies Sabicea brasiliensis e $S$. verticilata.
No primeiro ano agrícola $(2006 / 2007)$, o gênero Cyperus spp. apresentou o terceiro maior IVI $(27,97)$ aos 60 DAS e o maior IVI $(175,2)$ no terceiro ano agrícola $(2008 / 2009)$, sendo este o maior IVI de todos os anos de estudo (Tabelas 3 e 4). Esses resultados indicam que esse gênero foi eficiente na distribuição e acúmulo de biomassa na área diante das condições ambientais e de manejo no decorrer dos três anos agrícolas. Particularmente, no terceiro ano agrícola as condições ambientais favoreceram esse gênero, cujos percentuais pluviométricos foram $140 \%$ a mais do normal climatológico no referido município (Boletim Meteorológico, 2009).

Entre as espécies do gênero Cyperus identificadas, verificou-se que $C$. flavus apresentou o quarto e o terceiro maior IVI, respectivamente no segundo e terceiro anos agrícolas. C. iria foi a espécie com o segundo maior IVI no terceiro ano agrícola (Tabela 4). Essas espécies foram favorecidas pelo uso do arado nesses anos agrícolas, que promoveu a disseminação de suas sementes. Conforme Jakelaitis et al. (2003), para espécies que se reproduzem por sementes, o preparo convencional do solo incorpora estas de modo mais uniforme no perfil trabalhado, proporcionando a distribuição horizontal e vertical das sementes das plantas daninhas.

C. diffusus representou a espécie com o terceiro maior IVI tanto aos 30 como aos 
60 DAS do segundo ano agrícola (2007/2008). Nos dois períodos de avaliação, o IVI teve principal contribuição da De.R e Fr.R, com baixos valores de Do.R. A Fr.R dessa espécie é a maior da comunidade aos 30 DAS e a segunda maior aos 60 DAS (Tabela 4). Leal et al. (2006) constataram a presença de $C$. diffusus e Cyperus sphacelatus com maior frequência em área queimada. Para Marques et al. (2010), C. diffusus apresentou altos valores de IVI em área manejada com cobertura triturada, e a De.R foi o parâmetro mais importante. $O$ alto valor da Fr.R na área queimada pode ser justificado pela falta de cobertura vegetal e pela prática da aração.

As espécies remanescentes da vegetação secundária, agrupadas como plantas de capoeira, tiveram destaque no primeiro ano agrícola, com IVI de 13,88 e 15,30 aos 30 e 60 DAS, respectivamente (Figura 1). No segundo ano agrícola (2007/2008), a importância das plantas de capoeira começou a diminuir, ocorrendo apenas aos 30 DAS com IVI $=7,09$, e no terceiro ano agrícola (2008/2009) não foi registrada (Figura 1). Os indices fitossociológicos de maior contribuição para o IVI foram Fr.R e Do.R. Segundo Denich et al. (2005), a perda do potencial regenerativo das plantas de capoeira é resultado do intenso uso da terra, que danifica os sistemas radiculares e reduz a vitalidade dessas espécies. Leal et al. (2006) afirmam que a frequência do fogo, nas áreas a serem preparadas para cultivo, pode causar um processo de savanização, reduzindo o aparecimento de espécies arbóreas. Para Gehring et al. (2005), as florestas secundárias representam um ecossistema muito sensivel, pois um moderado aumento no uso da terra poderá levar à degradação e, dessa forma, prejudicar o desempenho de culturas anuais, como macaxeira, arroz e feijão-caupi.

No decorrer dos três anos agrícolas, a composição da comunidade infestante foi variável. $\mathrm{O}$ indice de similaridade revelou que houve similaridade entre as espécies apenas aos 30 e 60 DAS de cada ano agrícola e ausência de similaridade entre os anos agrícolas (Figura 2). Essa ausência de similaridade entre as espécies corrobora as perspectivas de mudança de composição florística indicadas pelos índices fitossociológicos, cuja alteração na composição pode estar associada, entre outros fatores, ao manejo.

A composição florística da comunidade infestante mudou no decorrer dos ciclos produtivos em razão das alterações das culturas e

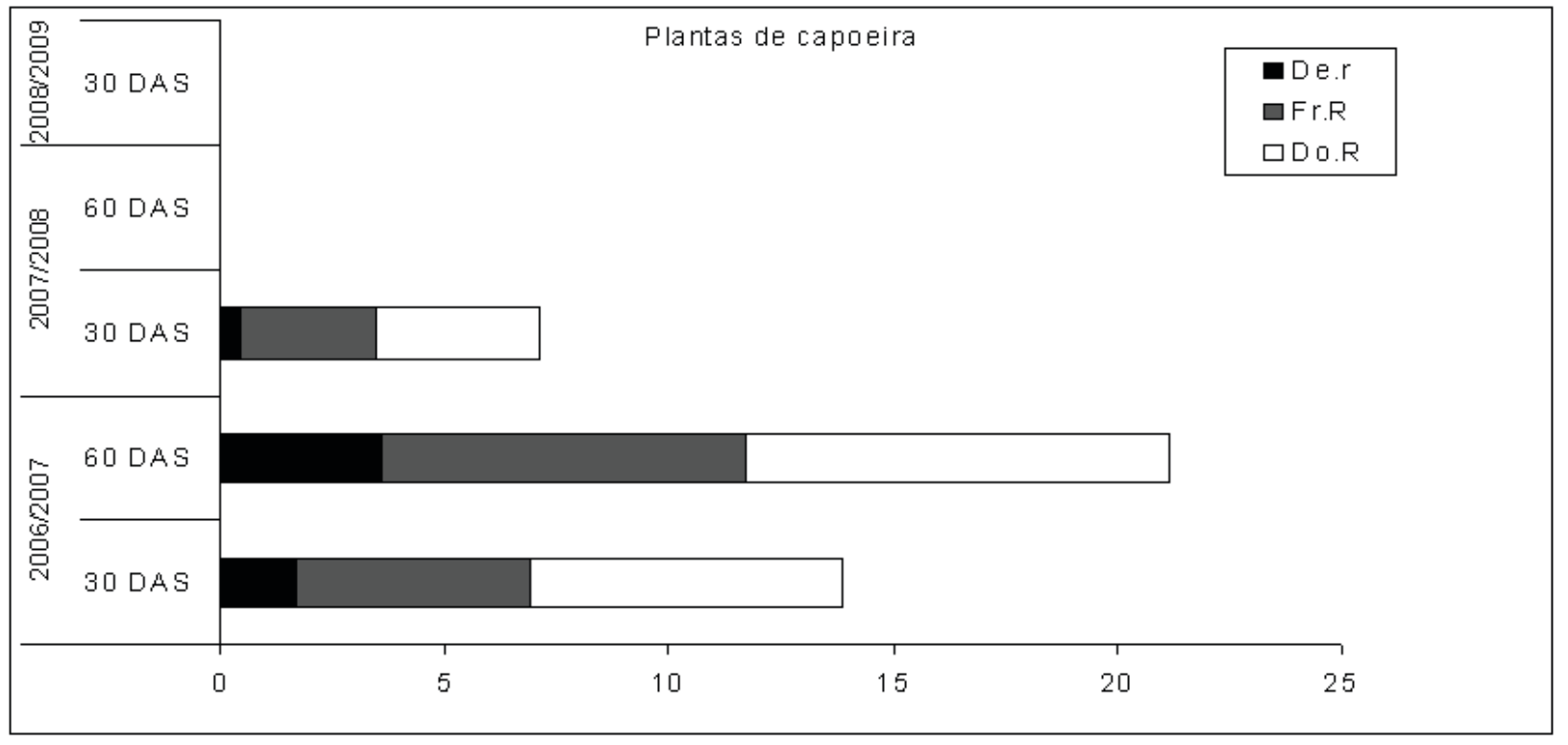

Figura 1 - Índice de valor de importância (IVI), densidade relativa (De.R), frequência relativa (Fr.R) e dominância relativa (Do.R) das plantas de capoeira nos anos agrícolas de 2006/2007 (cultivo de feijão-caupi no sistema de corte e queima) e 2008/2009 e 2007/ 2008 (cultura do feijão-caupi e mandioca, respectivamente, com preparo da área com arado). 


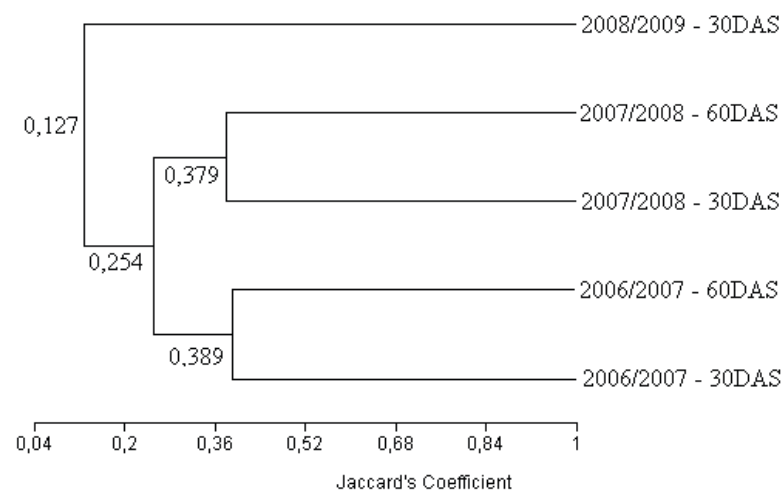

Figura 2 - Dendrograma de similaridade florística entre os períodos e anos de coleta pelo método de média de grupo (UPGMA), utilizando como coeficiente o índice de Jaccard. Ano agrícola 2006/2007 (cultivo de feijão-caupi em sistema de corte e queima). Anos agrícolas 2007/2008 e 2008/2009 (cultivo de mandioca e feijão-caupi, respectivamente, com preparo da área com arado). Município de Zé Doca-MA.

práticas de manejo . O corte e queima reduziu a diversidade das plantas daninhas, com seleção de espécies mais agressivas, como I. brasiliensis e S. glomerata. Os sucessivos cultivos com a aração eliminou as plantas de capoeira, mudou a composição específica das plantas daninhas e selecionou as espécies da família Cyperaceae. As espécies que apresentaram o maior IVI foram S. glomerata e I. brasiliensis após corte e queima, no cultivo de feijão-caupi, para o ano agrícola de 2006/ 2007; Juncus sp., C. diffusus, C. flavus, $S$. verticillata e $A$. americana, após preparo da área com arado, no cultivo de mandioca, para o ano agricola de 2007/2008; Cyperus sp., C. iria e C. flavus, após preparo da área com arado, no cultivo de feijão-caupi, para o ano agrícola de 2008/2009.

\section{AGRADECIMENTOS}

À CAPES, pela concessão da bolsa, à Embrapa Meio Norte, Embrapa Amazônia Oriental, Universidade Estadual do Maranhão, ao Programa de Pós-Graduação em Agroecologia e ao proprietário da área, sr. Chico.

\section{LITERATURA CITADA}

ARAUJO, J. C. et al. Supressão de plantas daninhas por leguminosas anuais em sistema agroecológico na préamazônia. Planta Daninha, v. 25, n. 2, p. 267-275, 2007.
BOLETIM METEOROLÓGICO ESPECIAL 2009.

Disponível em $<$ http://www.nemrh.uema.br/meteoro/boletins/ bltesp2009.pdf $>$. Acesso em: 10 jun. 2010.

CARVALHO, M. M. et al. Correção da acidez do solo e controle do capim-sapé. R. Bras. Zootec., v. 29, n. 1, p. $33-39,2000$

CURTIS, J. T.; MC INTOSH, R. P. The interrelations of certain analytic and synthetic phytosociological characters Ecology, v. 31, p. 434-435, 1950.

DENICH, M. et al. A concept for the development of fire-free fallow management in the Eastern Amazon, Brazil. Agric.

Ecosyst. Environ., v. 110, n. 1, p. 43-58, 2005.

FREITAS, F. C. L. et al. Interferência de plantas daninhas na cultura do feijão-caupi. Planta Daninha, v. 27, n. 2, p. $241-247,2009$.

GALINDO, I. C. L. et al. Relações solo-vegetação em áreas sob processo de desertificação no município de Jataúba, PE R. Bras. Ci. Solo, v. 32, n. 3, p. 1283-1296, 2008.

GEHRING, C.; DENICH, M.; VLEK, P. G. Resilience of secondary forester growth after slash-and-burn agriculture in central Amazonia. J. Trop. Ecol., v. 21, n. 5, p. 519-527, 2005.

\section{GERÊNCIA DE PLANEJAMENTO E} DESENVOLVIMENTO ECONÔMICO - GEPLAN. Atlas do Maranhão. Laboratório de Geoprocessamento. São Luís: Universidade Estadual do Maranhão, 2002. 32 p.

IKEDA, F. S. et al. Banco de sementes em cerrado sensu stricto sob queimada e sistemas de cultivo. Pesq. Agropec. Bras., v. 43, n. 6, p. 667-673, 2008

JAKELAITIS, A. et al. Dinâmica populacional de plantas daninhas sob diferentes sistemas de manejo nas culturas de milho e feijão. Planta Daninha, v. 21, n. 1, p. 71-77, 2003.

JOHANNS, O.; CONTIERO, R. L. Efeitos de diferentes períodos de controle e convivência de plantas daninhas com a cultura da mandioca. R. Ci. Agron., v. 37, n. 3, p. 326-331, 2006.

LEAL, E. C.; VIEIRA, I. C. G.; KATO, M. S. A. Banco de sementes em sistemas de produção de agricultura com queima e sem queima no município de Marapanim, Pará. B. Museu Paran. Emílio Goeldi, v. 1, n. 1, p. 19-29, 2006.

MAGURRAN, A. E. Ecological diversity and its measurement. Londres: Princeton University Press, 1988. $192 \mathrm{p}$. 
MARQUES, L. J. P. et al. Composição florística de plantas daninhas na cultura do feijão-caupi no sistema de capoeira triturada. Planta Daninha, v. 28, p. 953-961, 2010. (Número Especial)

MEIRA NETO, J. A. A. et al. Composição florística, espectro biológico e fitofisionomia da vegetação de muçununga nos municípios de caravelas e Mucuri, Bahia. R. Árvore, v. 29, n. 1, p. 139-150, 2005.

MUELLER-DOMBOIS, D.; ELLEMBERG, H. Aims and methods of vegetation. Ecology. New York: John Willey \& Sons, 1974. 547 p

OLIVEIRA, A. P. et al. Rendimento de feijão-caupi em função de doses e formas de aplicação de nitrogênio. Hortic. Bras., v. 21, n. 1, p. $77-80,2003$.
PITELLI, R. A. Estudos fitossociológicos em comunidades infestantes de agroecossistemas. J. Conseb, v. 1, n. 3, p. 1-7, 2000 .

RODER. W.; PHENGCHANH. S.; KEOBULAPHA, B. Weeds in slash-and-burn rice fields in northern Laos. Weed Res., v. 37, n. 2, p. 111-119, 1997.

RODRIGUES, M. A. C. M.; MIRANDA, I. S.; KATO, M. S. A. Flora e estrutura da vegetação secundária após o uso de diferentes trituradores florestais. Pesq. Agropec. Bras., v. 42, n. 4, p. 459-465, 2007.

SHEPHERD, G. J. FITOPAC 1: manual do usuário. Campinas: UNICAMP/Departamento de Botânica, 1994. 